\title{
Flupenthixol in Relapse Prevention in Schizophrenics with Comorbid Alcoholism: Results from an Open Clinical Study
}

\author{
Michael Soyka ${ }^{a}$ Claus Aichmüllera Ulrich v Bardeleben ${ }^{c}$ Manfred Beneked \\ Thomas Glaser ${ }^{d}$ Sybille Hornung-Knobel ${ }^{b}$ Ulrike Wegnera \\ on behalf of the study group \\ aPsychiatric Hospital University of Munich, Munich, bHaar Mental State Hospital, Haar, Germany; \\ cPsychiatric Hospital, University of Basel, Basel, Switzerland; dBayer Vital, Leverkusen, Germany
}

\section{Key Words}

Alcoholism · Flupenthixol · Relapse prevention •

Schizophrenia

\begin{abstract}
Substance use, especially alcoholism, has been recognized as a significant problem in schizophrenic patients, though only a few studies on the effects of pharmacotherapy in these patients have been conducted so far. The thioxanthene neuroleptic flupenthixol, which can be given intramuscularly (i.m.) for improving compliance, has been studied as a possible anti-craving drug both in animal models of alcoholism and some clinical studies. Pilot studies suggest that comorbid schizophrenics with substance use may benefit from treatment with flupenthixol. Efficacy of flupenthixol (10-60 mg i.m.) in reducing alcohol consumption of dual diagnosis patients was studied in an open 6-month clinical trial in 27 schizophrenics with comorbid alcoholism. Twenty-one patients entered the intention-to-treat analysis. Fourteen subjects were completers, 13 dropped out. Six patients completely abstained from alcohol during treatment. Alcohol consumption was significantly reduced compared
\end{abstract}

to baseline ( 4 weeks before treatment as measured by timeline follow-back interview). In general, while patients showed a marked improvement concerning alcohol consumption, only a slight improvement in psychopathology was recorded. Overall tolerability was good. These data indicate a probable beneficial effect of flupenthixol in schizophrenic patients with comorbid alcoholism. Although the efficacy of flupenthixol as an anti-craving drug in dual diagnosis patients has to be explored in further studies, the drug may be considered a promising medication for these patients.

Copyright $\odot 2003$ S. Karger AG, Basel

There is substantial evidence now that substance use, especially alcoholism, is a significant problem in schizophrenia, with prevalence estimates of $30-50 \%$ in clinical samples [9, 21, 38, 46, 48, 49, 62]. The term 'dual diagnosis patients' has been introduced to describe this type of patient. High prevalence estimates for alcoholism in schizophrenia have been reported in numerous clinical samples and various regions [for reviews see 15, 46, 62, 65, 68, 69]. Prevalence estimates for alcoholism clearly exceed those for other drugs of abuse but are compara-

\begin{tabular}{ll}
\hline KARGER & (c) 2003 S. Karger AG, Basel \\
1022-6877/03/0092-0065 $\$ 19.50 / 0$ \\
$\begin{array}{l}\text { Fax +41 61306 1234 } \\
\text { E-Mail karger@karger.ch } \\
\text { www.karger.com }\end{array}$ & $\begin{array}{l}\text { Accessible online at: } \\
\text { www.karger.com/ear }\end{array}$
\end{tabular}

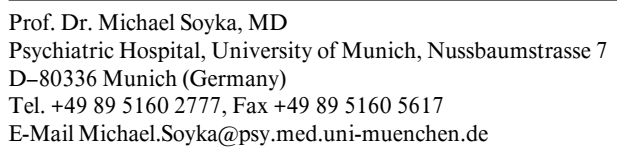

Prof. Dr. Michael Soyka, MD D-80336 Munich (Germany)

E-Mail Michael.Soyka@psy.med.uni-muenchen.de 
tively high for cannabis and cocaine [49]. Clear evidence for a significant comorbidity of alcoholism and schizophrenia comes especially from the Epidemiological Catchment Area Study, which reported a 4-fold increased risk for alcoholism in schizophrenia [24, 56]. Clinical studies indicate dual diagnosis schizophrenics to have a poor prognosis, notorious noncompliance, a young age of onset, male sex and severe social impairment, among others [35, 36, 65].

There is no consistent etiological theory to explain substance use in schizophrenia [47]. Apart from the self-medication hypothesis $[30,37]$, the role of neuroleptic side effects, social variables and specific neurobiological hypothesis (dysregulated neural integration of dopamine and glutamate signaling in the nucleus accumbens) have been stressed [8]. None of these hypotheses has been generally accepted.

The pharmacotherapy of comorbid schizophrenics with alcoholism has widely been neglected, and very few prospective controlled clinical trials have been performed to date $[61,66,78]$. The use of novel antipsychotics in the treatment of dual diagnosis patients has been advocated repeatedly [4], but few studies have been conducted so far $[11,79]$. The role of other antipsychotics in relapse prevention of substance use in schizophrenia and the interrelationship between changes in psychopathology and substance use in dual diagnosis patients has not been studied in great detail. The thioxanthene neuroleptic flupenthixol, a drug with mixed dopamine D1/D2 antagonistic properties as well as antagonistic properties at the serotonin $5-\mathrm{HT}_{2 \mathrm{~A}}$ receptors $[19,40,45]$, which is widely used for acute and long-term treatment of schizophrenia [20], has been studied as a possible anti-craving drug in a number of preclinical and clinical studies.

A broad number of preclinical and animal data suggest flupenthixol to attenuate the positive reinforcing and discriminative stimulus effects of cocaine [74], to decrease cocaine intake in rats $[31,43]$ and to block the discriminative stimulus and reinforcing effects of cocaine [52]. With respect to alcohol, animal data in rats also suggest a reduction of alcohol intake [70]. Flupenthixol has been successfully studied in the US as an anti-craving drug in cocaine/ crack consumers [17, 18, 29]. Positive effects of flupenthixol on alcohol as well as other drug intake have been reported in a uncontrolled study on 20 patients who received a daily dose of $0.5-1 \mathrm{mg}$ flupenthixol on a shortterm basis [53]. However, a recently finished placebo-controlled study in nonpsychotic alcoholics (flupenthixol decanoate $10 \mathrm{mg}$ every 14 days) showed unfavorable results [77].
More specifically, a beneficial effect of flupenthixol decanoate in dual diagnosis schizophrenics has been reported in a case report [71] and an open clinical trial [58]. More recently, Levin et al. [39] studied flupenthixol decanoate (40 mg every 14 days) in schizophrenic patients who were also cocaine users $(n=8)$ and demonstrated increases in cocaine-negative urine analysis, as well as improved psychopathology (decrease in negative and depressive symptoms).

We report the results of an open controlled clinical trial to assess possible anti-craving and relapse prevention effects of flupenthixol in schizophrenic patients with comorbid alcohol use.

\section{Methods}

This was an open exploratory multicenter 6-month trial without a control group to investigate the relapse prevention and antipsychotic efficacy of flupenthixol decanoate in schizophrenic patients with secondary alcohol abuse or dependency. The primary objective was to investigate whether a reduction in the average consumption of alcohol can be achieved by treatment with flupenthixol decanoate. The primary efficacy variable was the average quantity of alcohol consumption during treatment with flupenthixol decanoate as compared to the 4 weeks prior to study entry, measured with the timeline follow-back interview [TFLB; 63]. The study was conducted from July 1997 through December 1999 in 6 psychiatric hospitals in Germany and Switzerland. Patients were seen on a 4-week basis at seven times throughout the trial [visit 1 (V1) took place in week 0, visit 7 (V7) in week 24).

\section{Inclusion Criteria}

Patients had to meet the ICD-10 diagnostic criteria for schizophrenia (F 20.0-20.09), be aged between 20 and 55 years and had to have suffered from moderate to severe alcohol dependence for at least 2 years (F 10.2). Successful completion of detoxification (no withdrawal symptoms at baseline) 2 weeks before entering the trial, negative drug screening, written informed consent, and normal EEG and ECG readings were also required. At baseline the Munich Alcoholism Screening Test (MALT) was administered to verify diagnosis of alcohol dependence [14].

\section{Exclusion Criteria}

Psychiatric disorders not consistent with the diagnosis of schizophrenia and concurrent alcohol dependence, neoplasm within the past 5 years, treatment with flupenthixol in the 3 months prior to the study, known intolerability of the drug or contraindication of treatment with flupenthixol, administration of long-acting depot neuroleptics 4 weeks prior to treatment (haloperidol decanoate: 8 weeks), abuse of or dependence on other drugs in the last year preceding treatment, clinically relevant medical or neurological disorders requiring long-term therapy, e.g. insulin-dependent diabetes, severe impairment of liver function (coagulopathy), advanced liver cirrhosis, severe cardiac or pulmonary diseases, renal failure, no fixed address, concomitant treatment with the following medications: unregistered medications, all psychoactive, including anticonvulsive
66

Eur Addict Res 2003;9:65-72
Soyka/Aichmüller/v Bardeleben/Beneke/ Glaser/Hornung-Knobel/Wegner 
drugs (exceptions: biperiden, promethazine and/or lormetazepame for sleep disorders, lorazepam for anxiety, antidepressants if necessary) or medication for treatment of alcoholism including acamprosate, naltrexone, clomethiazole were exclusion criteria. Patients who were scheduled for a standardized inpatient treatment were also excluded from the trial. The study was conducted according to the guidelines of Good Clinical Practice (GCP) and approved by the local Ethics Committees.

\section{Treatment}

All subjects were treated with flupenthixol decanoate for a maximum of 24 weeks. Intramuscular injections of the medication were administered every 2 weeks. All 27 subjects enrolled received at least 1 injection. Compliance was assured as the injections were administered by the investigators. The dose could be adjusted individually (between 10 and $60 \mathrm{mg}$ every two weeks) according to clinical demand and the clinician's decision. The medication was provided in ampoules containing $0.5 \mathrm{ml}=10 \mathrm{mg}$ flupenthixol decanoate. The occurrence of a relapse was not an a priori reason for a premature withdrawal from the study.

\section{Compliance}

Blood samples were drawn at visits 3 and 7 for the determination of serum concentrations.

\section{Efficacy and Safety Variables}

All efficacy and safety variables were assessed on a 4-week basis throughout the trial. A German version of the TFLB protocol $[6,7$, 63] was used to assess self-reported alcohol consumption 4 weeks prior to and throughout the trial. In addition, a German version [42, 54] of the Obsessive Compulsive Drinking Scale (OCDS) was used to measure craving [1].

Psychopathology was assessed with the Positive and Negative Syndrome Scale [PANSS; 28] and the Clinical Global Impression (CGI; NIMH 1976) Scale (secondary variables). Extrapyramidal symptoms were measured by the AIMS scale [22], changes in social functioning be thy 8-item self-report social functioning questionnaire [SFQ; 75].

\section{Statistics}

Descriptive statistics were used to evaluate the quantitative variables. Alcohol consumption, craving and psychopathological status were analyzed by correlation statistical analyses.

For all quantitative variables, means, standard deviations, minimum, median and maximum were computed. Frequency counts and percentages were generated for qualitative variables. Repeated measurements of some selected variables were analyzed on an exploratory basis using paired $t$ tests. No confirmatory analyses were conducted. All analyses were conducted with the SAS version 6.12 program package.

The intention to treat (ITT) sample included all patients with baseline values, one injection of the study medication and at least 1 follow-up visit. The valid for efficacy (VfE) group completed the study according to protocol. Patients who prematurely terminated the study were included with their last available measurement, which was then used as final outcome. Changes in variables of special interest were analyzed by $t$ test.

Adverse events were classified according to COSTART and grouped according to the body systems affected.

Flupenthixol in Relapse Prevention in

Alcoholic Schizophrenics

\section{Results}

During the recruitment period 27 patients were enrolled in the trial (safety analysis). Twenty-one subjects were included in the ITT, of which 14 subjects (the VfE population) completed the 6-months study period. Thirteen patients were dropouts. Reasons for premature termination were lost to follow-up ( $\mathrm{n}=7)$, withdrawal of consent $(n=4)$, adverse event (severe akathisia; $n=1)$ and bad compliance $(n=1)$.

Baseline demographics are given in table 1. Seventeen $(63 \%)$ of the 27 patients were male, 10 (37\%) female. In the VfE group $8(57 \%)$ patients were male, $6(43 \%)$ female. Mean age of the VfE population was 32.0 (23-58) years, BMI was $23.5(17-29.3) \mathrm{kg} / \mathrm{m}^{2}$. With respect to schizophrenic subtype, most VfE patients were diagnosed as paranoid subtype $(\mathrm{n}=12 ; 86 \%), 1$ patient had a catatonic (7\%), another one a schizoaffective psychosis (7\%).

All patients showed marked to severe alcohol dependence. For the ITT sample, 5 (SD 1.12) out of the 6 ICD10 criteria were fulfilled (VfE sample: $5.0 \pm 1.07$ ). MALT score was $27.64( \pm 6.39)$, indicating severe alcohol dependence.

The 21 ITT patients had had a daily alcohol consumption of more than $150 \mathrm{ml}$ pure alcohol (females: $120 \mathrm{ml}$ ) over a period of several months, 12 patients had had a maximum consumption of more than 300 (females: 240) $\mathrm{ml}$ on several days a month.

Mean flupenthixol dosage given was $30.4 \mathrm{mg}$ every 2 weeks to the ITT sample (VfE sample: $32.2 \mathrm{mg}$ ). Mean duration of treatment in the VfE group was 170 (166183) days. During treatment with flupenthixol, 10 patients $(71 \%)$ received short-term concomitant psychopharmacological medication: 6 subjects received biperiden, 6 psycholeptics and 4 were on antidepressants (doxepine, amitryptilin, nefazodone, paroxetine). No switch to benzodiazepines or other drugs of abuse could be detected.

\section{Efficacy}

Alcohol Consumption. Fourteen of the 21 patients $(60 \%)$ of the ITT sample completed the study. Six of them remained completely abstinent throughout the trial, 2 patients reported a reduced consumption during treatment compared to baseline, 3 patients were relapsers at 2 or 3 visits, 3 patients on more than 3 visits. Eight patients were abstinent at study end. Alcohol consumption in standard drinks/day as measured by TFLB decreased significantly over time (fig. 1). In addition, the mean number of relapses to heavy alcohol consumption and the number of 
Table 1. Sociodemographic baseline characteristics

\begin{tabular}{lccc}
\hline Demographics & $\begin{array}{l}\text { VfE } \\
n=14\end{array}$ & $\begin{array}{l}\text { ITT } \\
\mathrm{n}=21\end{array}$ & $\begin{array}{l}\text { Safety } \\
\mathrm{n}=27\end{array}$ \\
\hline Male & $8(57.1)$ & $15(71.4)$ & $17(63.0)$ \\
Female & $6(42.9)$ & $6(28.6)$ & $10(37.0)$ \\
Age, years & $42.0 \pm 10.56$ & $43.10 \pm 10.59$ & $42.22 \pm 10.07$ \\
Height, cm & $172.93 \pm 10.30$ & $173.33 \pm 9.33$ & $172.11 \pm 8.78$ \\
Weight, kg & $70.89 \pm 14.70$ & $71.40 \pm 13.05$ & 71.80 \\
BMI, kg/m & $23.54 \pm 3.58$ & $23.75 \pm 3.37$ & 24.17 \\
Caucasian & 12 & 19 & 25 \\
Black & 2 & 2 & 2 \\
Smoker & & & \\
$\quad$ No & 1 & 3 & 4 \\
$\quad$ Yes & 13 & 18 & 23 \\
Diagnosis & & & \\
Schizophrenic subtype & & $17(81.0)$ & $20(74.1)$ \\
$\quad$ Paranoid & $12(85.7)$ & $1(4.8)$ & $2(7.4)$ \\
$\quad$ Hebephrenic & - & $1(4.8)$ & $1(3.7)$ \\
$\quad$ Catatonic & $1(7.1)$ & $1(4.8)$ & $1(3.7)$ \\
$\quad$ Simplex & - & $1(4.8)$ & $3(11.1)$ \\
$\quad$ Schizoaffective & $1(7.1)$ & $8.52 \pm 6.56$ & $9.70 \pm 7.58$ \\
Years since diagnosis & $7.36 \pm 4.31$ & $3.65 \pm 2.68$ & $4.00 \pm 2.86$ \\
Relapse since diagnosis & $4.00 \pm 2.80$ & $2.72 \pm 3.51$ & $2.45 \pm 3.29$ \\
Years since last inpatient treatment & $2.82 \pm 3.12$ & & \\
\hline
\end{tabular}

Mean \pm SD or percentages (shown in parentheses). drinks per relapse decreased after initiation of treatment (fig. 2). In patients who relapsed, the mean number of drinks per relapse dropped from 7.7 ( \pm 5.8 ) drinks to 4.4 ( \pm 3.2) drinks during the initial study phase and remained reduced throughout the study. The percentage of abstinent days during treatment also increased significantly during treatment (fig. 3). Craving scores, as measured by OCDS, decreased significantly between visits 1 and 2 , and continuously remained on a reduced level throughout treatment (fig. 4).

Psychopathology. General assessment of the VfE subjects as documented in the CGI revealed that at the end of the study $50 \%$ were very much or much improved, $21 \%$ were unchanged or had slightly worsened. In line with these results, social functioning of the patients as measured by the SFQ had improved by $30 \%$. The mean sum scores of the SFQ decreased from 9.07 (V1) to 6.79 (V2) and ended at 6.18 at $\mathrm{V} 7$, indicating an enhanced social functioning.

Results of the PANSS subscales (positive symptoms, negative symptoms, global) and the BPRS score only slightly decreased over time (fig. 5).
Safety Analysis. Out of the 27 patients who received at least one injection of study medication, 9 subjects (33\%) reported at least 1 adverse event (AE). Six of these individuals suffered from $1 \mathrm{AE}$, the remaining three had 2, 3 and 5 AEs. In total, 16 adverse events were recorded: akathisia (19\%), nervousness (19\%), extrapyramidal symptoms $(12 \%)$, insomnia $(6 \%)$, neuropathy $(6 \%)$. Body systems affected were 'body as a whole' (recorded in $25 \%$ of AEs) and 'digestive' and 'special senses', recorded in $6 \%$. Of the 16 AEs, $12 \%$ were rated as possibly related to study medication, $43 \%$ as probably, $37 \%$ as improbably related to the medication, and $6 \%$ as not assessable.

Extrapyramidal motor side effect rating as assessed with the AIMS was remarkably low. The mean summary scores (items 1-7) decreased from 1.57 (SD 2.65) at baseline to $1.14[2,54]$ at V5 but returned to $1.64[3,20]$ at endpoint (V7). At least 8 subjects of the VfE sample scored zero at all control visits. The mean global assessment score was slightly enhanced from 0.71 (SD 1.20) at baseline to $1.50[3,32]$ at $\mathrm{V} 5$ and $1.43[2,68]$ at endpoint.

Two subjects showed a significant adverse event (akathisia or parkinsonoid), the former terminated the study prematurely for this reason. 

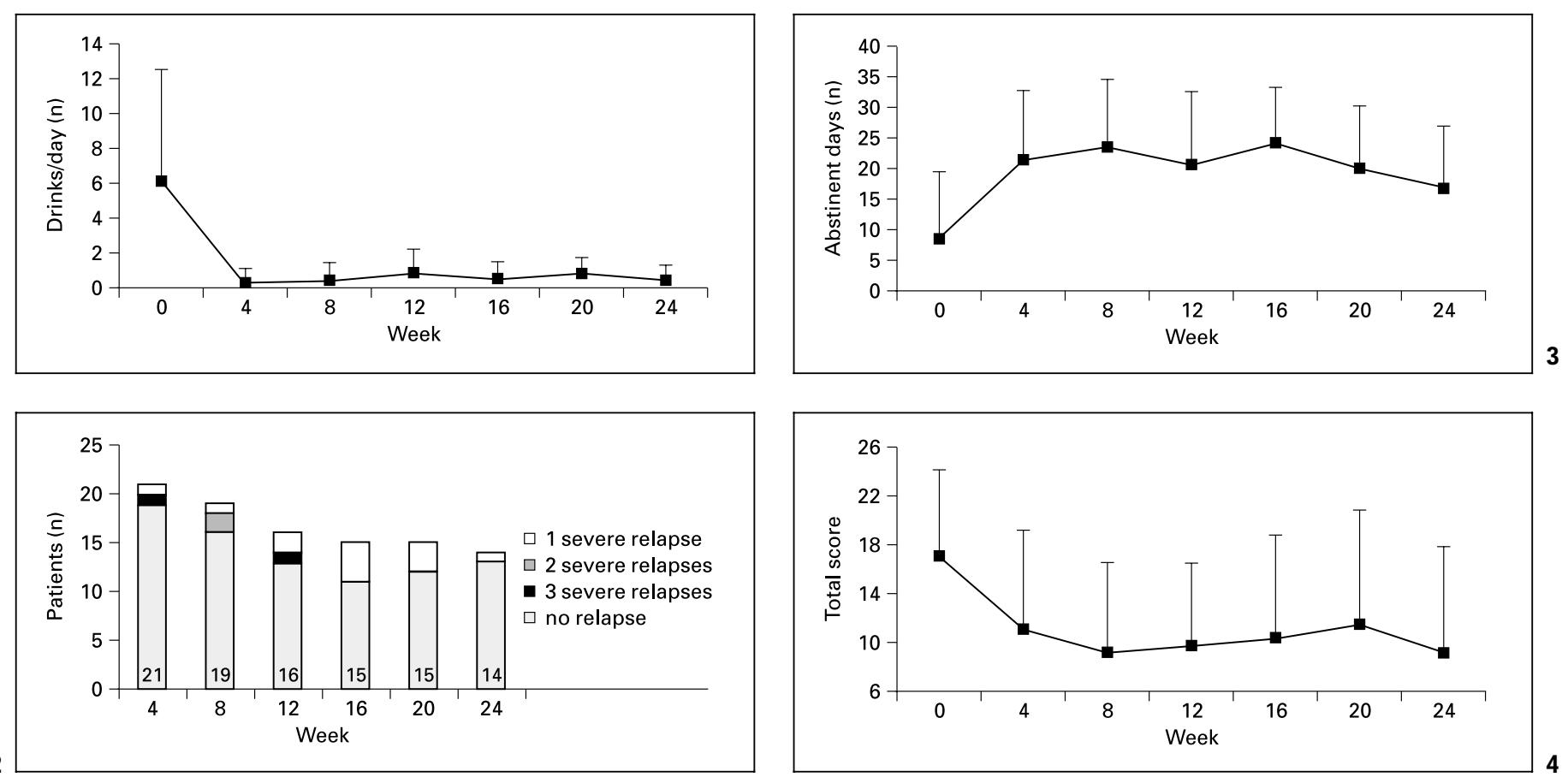

Fig. 1. Number of drinks during treatment (ITT sample).

Fig. 2. Number of relapses during treatment. Figures inside bars indicate total number of patients still participating.

Fig. 3. Number of abstinent days per 4-week interval during treatment.

Fig. 4. Craving scores (mean scores OCDS) during treatment.

Fig. 5. PANSS and BPRS scores during treatment (VFE sample).

Serum concentrations of flupenthixol measured were rather low and, in some cases, close to the detection limit $(0.1 \mathrm{ng} / \mathrm{ml})$ The mean concentration was $0.21(0.1-0.46)$ $\mathrm{ng} / \mathrm{ml}(\mathrm{V} 3)$ and $0.22 \mathrm{ng} / \mathrm{ml}(0.1-0.83 ; \mathrm{V} 7)$, respectively.

\section{Discussion}

Substance use has been recognized as a major problem, affecting compliance and treatment outcome. A number of dual diagnosis treatment programs has been introduced over the past decade for this newly recognized type of patients $[2,12,23,25]$, while the pharmacotherapy of these patients has widely been neglected.

The present study was designed to examine possible relapse prevention effects of the thioxanthene flupenthix-

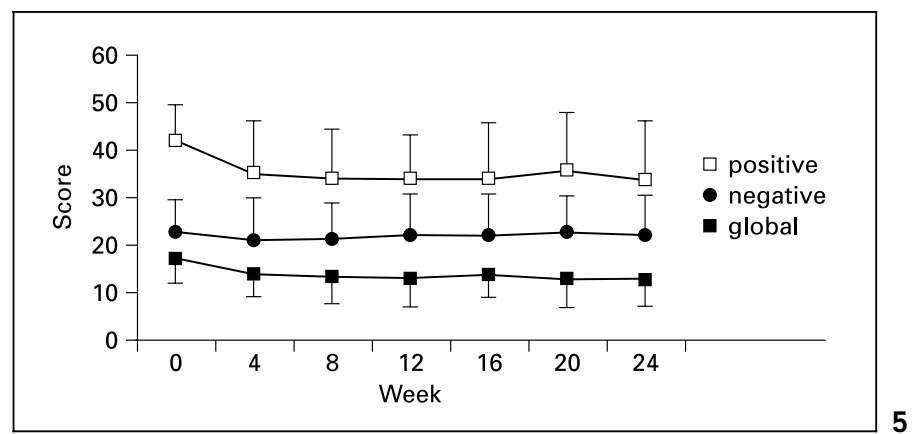

ol in schizophrenics with comorbid alcoholism, and to explore a possible interrelationship between improvement of psychopathology and alcohol use. Twenty-seven patients were included in this 6-month study, 21 patients were eligible for ITT analysis, 13 patients were dropouts. The efficacy data from this study as measured by TLFB $[7,63]$ showed a significant reduction of alcohol consumption behavior compared to the 4-week baseline period before treatment. Six patients remained completely abstinent throughout the trial. In addition, craving as measured by a visual analogue scale and the OCDS [1, 54], was markedly decreased following initiation of treatment. Results from this exploratory study should be discussed with caution due to the small number of patients included and the open label design of the study. Limitations also arise from the dropout rate of approximately 
$50 \%$, which is similar to the dropout rates in pharmacological studies with anti-craving drugs in nonpsychotic alcoholics [67]. In addition, the efficacy of craving scales like the OCDS in predicting relapse in alcoholics has not been firmly established [34]. Still, the overall observed clinical effects seem remarkable, especially in the light of the treatment outcomes and compliance rates in dual diagnosis schizophrenics (cited above). Interestingly, while the antialcoholic effect of flupenthixol could clearly be demonstrated, only a slight improvement in the psychopathology of the substance-using patients could be noticed. The therapeutic effect of flupenthixol did not seem to be related to an overall improvement of psychopathology, thus questioning to some extent the self-medication hypothesis of substance use in schizophrenia [30]. This question deserves further attention. Substance use has been associated with the patients' wish to improve psychopathological symptoms, such as anhedonia [55], or side effects of neuroleptic treatment. A number of findings question this hypothesis [3], and the empirical evidence is small $[65,72]$.

Two more general aspects may also be generated from this study. First, although the mean dosage given $(32 \mathrm{mg} /$ 14 days) was higher than the one usually given in relapse prevention for schizophrenia [ $20 \mathrm{mg}$; 32], the serum concentrations of flupenthixol measured were lower than those usually found in schizophrenics [26, 27, 73]. Low neuroleptic serum concentrations in alcoholic schizophrenics have also been reported in other studies [64] and may be explained by an accelerated metabolism of the drug in these patients, but this topic warrants further studies. For dual diagnosis patients, measurement of plasma levels can be recommended for verifying compliance or variations in metabolism of neuroleptics.

Second, although dual diagnosis patients are notorious for noncompliance $[65,68]$, the dropout rate in this study was not higher than those in pharmacological studies with nonpsychotic alcoholics [33]. Clearly, more pharmacological studies in dual diagnosis patients following a core protocol are needed to explore pharmacological options and risks in these patients.

A consistent theory explaining the apparently increasing number of dual diagnosis patients has not been put forward, but medication effects clearly play a significant role in the development and treatment of substance use in schizophrenia. A number of different pharmacological treatment options can be discussed with respect to substance use in schizophrenia: (1) use of conventional antipsychotics to improve psychopathology, thus reducing the relapse risk in dual diagnosis patients; (2) use of atypical neuroleptics to improve negative symptomatology and avoid side effects, possibly leading to substance use; (3) use of antidepressants or other drugs to improve depression or anhedonia [59,60,61], and (4) use of novel anti-craving drugs, such as acamprosate or naltrexone.

Only the first two options have been addressed in a number of recent studies. To date, the empirical basis for psychopharmacology in dual diagnosis patients is small. The role of 'conventional' neuroleptics in the development and treatment of substance use in schizophrenia has been discussed with some concern. On the one hand researchers have argued them to precipitate or worsen substance use $[61,76]$. Dual diagnosis patients may be more prone to the side effects of neuroleptic treatment, such as tardive dyskinesia and, especially, akathisia [10, $13,57,62]$, while in the present study the incidence of akathisia and extrapyramidal side effects was remarkably low. On the other hand the empirical basis for a beneficial effect of atypic neuroleptics such as clozapine in dual diagnosis patients [44] is very small. Only recently, in a retrospective survey of 43 patients, clozapine was reported to decrease substance use in schizophrenia [79]. In addition Drake et al. [11], in an a posteriori analysis of 151 patients with schizophrenia or schizoaffective disorder and co-occurring substance use, demonstrated that patients who received clozapine experienced significant reductions in the severity of their alcohol abuse. However, continuous substance use in schizophrenics under treatment with clozapine has been reported in some cases [71]. Since there are no depot formula for atypical neuroleptics yet, the question of noncompliance, crucial for the treatment of dual diagnosis patients, needs to be considered.

The results of this study are not in line with a recently published study by Wiesbeck et al. [77], who failed to demonstrate a clinical efficacy of flupenthixol in nonpsychotic alcoholics. The dosage of flupenthixol used in their study was much lower than the one used in the schizophrenic patients of the present trial, but differences in treatment outcome may not only be linked to dosage. They may also reflect different neurobiological mechanisms underlying the addiction process in schizophrenic and other alcoholics (e.g., the dopaminergic neurotransmission might function differently). In addiction, tolerability of the drug and side effects may also be different in schizophrenic and nonpsychotic alcoholics.

To date, flupenthixol may be considered to be a promising medication to study in dual diagnosis schizophrenics. In the light of the preclinical evidence, suggesting that relatively low doses of flupenthixol may attenuate alcohol and cocaine intake [70], further clinical testing of this 
compound in drug abuse/dependence disorders seems warranted, and should include a control group. Although low doses of flupenthixol can also cause extrapyramidal side effects in some cases [16], the clinical data available so far suggest that tolerance of flupenthixol is usually good in patients with substance abuse/dependence disorders. This is also supported by data from the present study. Most of the subjects of the ITT sample experienced no or only minimal EPS. Correspondingly, the mean AIMS scores at all visits were rather low. This finding is remark- able in the light of the mean dosage of $32.2 \mathrm{mg} / 14$ days, which is substantially above the recommended dose of $20 \mathrm{mg} / 14$ days used for relapse prevention [32].

\section{Acknowledgment}

The authors wish to thank all participating investigators from the Munich, Haar and Muenster trial units for their contribution. Furthermore, the excellent administrative work of H. Graumann and of the monitor P.-J. Tönnes is gratefully acknowledged.

\section{References}

1 Anton RF, Moak DH, Latham PK: The Obsessive Compulsive Drinking scale: A new method of assessing outcome in alcoholism treatment studies. Arch Gen Psychiatry 1996;53:225231.

2 Barrowclough C, Haddock G, Tarrier N, Lewis SW, Koring J, O’Brien R, Schofiled N, McGovern J: Randomized controlled trial of motivational interviewing, cognitive behavior therapy, and family intervention for patients with comorbid schizophrenia and substance use disorders. Am J Psychiatry 2001;158:1706-1713.

3 Brunette MF, Mueser KT, Xie H, Drake H: Relationships between symptoms of schizophrenia and substance abuse. J Nerv Ment Dis 1997;185:13-20.

4 Buckley P, Thompson P, Way L, Meltzer IIY: Substance abuse among patients with treatment-resistant schizophrenia: Characteristics and implications for clozapine therapy. Am J Psychiatry 1994;151:385-389.

5 Buckley PF: Novel antipsychotic medications and the treatment of comorbid substance abuse in schizophrenia. J Subst Abuse Treat 1997;15: 113-116.

6 Carey KB: Reliability and validity of the TimeLine Follow-Back Interview among psychiatric outpatients; A preliminary report. Psychol Addict Behav 1997;11:26-33.

7 Carney MA, Tennen H, Affleck G, Del Boca FK, Kranzler HR: Levels and patterns of alcohol consumption using timeline follow-back, daily diaries and real-time 'electronic interviews'. J Stud Alcohol 1998;598:447-454.

8 Chambers RA, Krystal JH, Self DW: A neurobiological basis for substance abuse comorbidity in schizophrenia. Biol Psychiatry 2001;7183.

9 Cuffel BJ: Prevalence estimates of substance abuse in schizophrenia and their correlates. $\mathrm{J}$ Nerv Ment Dis 1992;180:589-592.

10 Dixon L, Weiden PJ, Haas G, Frances AJ Increased tardive dyskinesia in alcohol-abusing schizophrenic patients. Compr Psychiatry 1992;33:121-122.

11 Drake RE, Xie H, McHugo GJ, Green AI: The effects of clozapine on alcohol and drug use disorders among patients with schizophrenia. Schizophrenia Bull 2000;26:441-449.
12 Drake RE, Mueser KT: Psychosocial approaches to dual diagnosis. Schizophrenia Bull 2000;26:105-118.

13 Duke PJ, Pantelis C, Barnes TRE: South Westminster Schizophrenia Survey. Alcohol Use and its relationship to symptoms, tardive dyskinesia and illness onset. Br J Psychiatry 1994; 164:630-636.

14 Feuerlein W, Ringer CH, Küfner H, Antons K: Diagnose des Alkoholismus. Der Münchener Alkoholismustest (MALT): MMW Munchn Med Wochenschr 1977;119:1275-1282.

15 Fowler IL, Carr VC, Carter NT, et al: Patterns of current and lifetime substance use in schizophrenia. Schizophrenia Bull 1998;24:443-455.

16 Fritze J, Spueda I: Tolerability of low dose neuroleptics: A case control study of flupenthixol. Eur Neuropsychopharmacol 1997;7:261-266.

17 Gawin FH, Allen D, Humblestone B: Outpatient treatment of 'crack' cocaine smoking with flupenthixol decanoate. Arch Gen Psychiatry 1989;46:322-325.

18 Gawin FH, Khalsa-Denison M, Jatlow P: Flupenthixol-induced aversion to crack cocaine. $\mathrm{N}$ Engl J Med 1996;334:1340-1341.

19 Glaser T, Sommermeyer H, Fassbender M, Mauler F: The receptor binding profile of cisflupentixol; in Glaser T, Soyka M (eds): Flupentixol - typisches oder atypisches Wirkspektrum? Darmstadt, Steinkopff, 1998 pp 9-21 (in German).

20 Glaser T, Soyka M (Hrsg): Flupentixol - Pharmakologie, antipsychotische Wirkung, neue Indikationen. Darmstadt, Steinkopff, 1998.

21 Graham HL, Maslin J, Copello A, Birchwood M, Mueser K, McGovern D, Georgiou G: Drug and alcohol problems amongst individuals with severe mental health problems in an inner city area of the UK. Soc Psychiatry Psychiatr Epidemiol 2001;448-455.

22 Guy W: Early Clinical Drug Evaluation Assessment Manual for Psychopathology. Rockville, National institute Mental Health, 1976.

23 Hellerstein DJ, Rosenthal RN, Miner CR: A prospective study of integrated outpatient treatment for substance-abusing schizophrenic patients. Am J Addict 1995;4:33-42.
24 Helzer JD, Pryzbeck TR: The co-occurrence of alcoholism with other psychiatric disorders in the general population and its impact on treatment. J Stud Alcohol 1988;49:219-224.

25 Ho AP, Tsuang JW, Liberman RP, Wang R, Wilkins JN, Eckman TA, Shaner AL: Achieving effective treatment of patients with chronic psychotic illness and comorbid substance dependence. Am J Psychiatry 1999;156:17651770.

26 Jørgensen A: Pharmacokinetik studies on flupenthixol decanoate, a depot neuroleptic of the thioxanthene group. Drug Metab Rev 1978;8: 235-249.

27 Jørgensen A: Serum concentrations of cis(Z)Flupentixol and prolactin in chronic schizophrenic patients treated with flupentixol and cis(Z)-Flupentixol decanoate. Psychopharmacology (Berl) 1982, 77:58-65.

28 Kay SR, Fiszbein A, Opler LA: The Positive and Negative Syndrome Scale (PANSS) for schizophrenics. Development and standardization. Schizophr Bull 1987;13:261-276.

29 Khalsa ME, Jatlow P, Gawin FH: Flupenthixol and desipramine treatment of crack users: Doule-blind Results; in CPDD Problems of drug dependence, vol 141, in NIDA Research Monographs. Washington, Department of Health and Human Services, pp 438-444.

30 Khantzian EJ: The self-medication hypothesis of substance use disorders: A reconsideration and recent applications. Harv Rev Psychiatry 1997;4:231-244.

31 King GR, Joyner C, Ellinwood EH: Continuous or intermittent cocaine administration: Effects of flupenthixol treatment during withdrawal. Pharmacol Biochem Behav 1994;49: 883-889.

32 Kissling W: Guidelines for neuroleptic relapse prevention. New York, Springer, 1991.

33 Kranzler HR, Escobar R, Lee DK, Meza E: Elevated rates of early discontinuation from pharmacotherapy trials in alcohol and drug abusers. Alcohol Clin Exp Res 1996;20:16-20.

34 Kranzler HR, Mulgrew CL, Modesto-Lowe V, Burleson JA: Validity of the Obesessive Compulsive Drinking Scale (OCDS): Does craving predict drinking behavior? Alcohol Clin Exp Res 1999;23:108-114. 
35 Krausz M, Mass R, Haasen C, Gross J: Psychopathology in patients with schizophrenia and substance abuse: A comparative clinical study. Psychopathology 1996;95-103.

36 Krausz M, Vertheim U, Degkwitz P: Psychiatric comorbidity in opiate addicts. Eur Addict Res 1999;55-62.

37 Krystal JH, D’Souza DC, Madonick S, Petrakis IL: Toward a rational pharmacotherapy of comorbid substance abuse in schizophrenia patients. Schizophrenia Res 1999;35(suppl):S35S49.

38 Lehman AF, Myers CP, Corty E, Thompson JW: Prevalence and patterns of 'dual diagnosis' among psychiatric inpatients. Compr Psychiatry 1994:35:1-5.

39 Levin FR, Evans SM, Coomaraswammy S, Collins ED, Regent N, Kleber HD: Flupenthixol treatment for cocaine abusers with schizophrenia: A pilot study. Am J Drug Alcohol Abuse 1998;24:343-360.

40 Leysen JE, Janssen PMF, Schotte A, Luyten MHML, Megens AAHP: Interaction of antipsychotic drugs with neurotransmitter receptor sites in vitro and in vivo in relation to pharmacological and clinical effects: Role of $5 \mathrm{HT}_{2}$ receptors. Psychopharmacology (Berl) 1993; 112:40-54.

41 Linszen DH, Dingemans PM, Lenior ME: Cannabis abuse and the course of recent-onset schizophrenic disorders. Arch Gen Psychiatry 1994;51:273-279.

42 Mann K, Ackermann K: Die OCDS-G: Psychometrische Kennwerte der deutschen Version der Obsessive Compulsive Drinking Scale. Sucht 2000;90-100.

43 Mansbach RS, Jortani SA, Balster RL: Antagonism of cocaine's reinforcing and discriminative stimulus effects by $\alpha$-flupenthixol. Exp Clin Psychopharmacol 1994;2:3-12.

44 Markus P, Snyder R: Reduction of comorbid substance abuse with clozapine. Am J Psychiatry 1995; $152: 959$.

45 Meltzer HY, Matsubara S, Lee JC: Classification of typical and atypical antipsychotic drugs on the basis of dopamine D-1, D-2 and serotonin2 pKi values. J Pharmacol Exp Ther 1989; 251:238-246.

46 Mueser KT, Bellack AS, Blanchard JJ: Comorbidity of schizophrenia and substance abuse: Implications for treatment. J Consul Clin Psychol 1992;60:845-856.

47 Mueser KT, Drake RE, Wallach MA: Dual Diagnosis: A review of etiological theories. Addict Behav 1998;23:717-734.

48 Mueser KT, Yarnold PR, Levinson DF, Singh H, Bellack AS, Kee K, Morrison RL, Yadalam KG: Prevalence of substance abuse in schizophrenia: Demographic and clinical correlates. Schizophrenia Bull 1990;16:31-56.

49 Mueser KT, Yarnold PR, Rosenberg SD, Swett C, Miles KM, Hill D: Substance use disorder in hospitalized severely mentally ill psychiatric patients: Prevalence, correlates, and subgroups. Schizophrenia Bull 2000, 26:179-192.
50 Mueser KT, Yarnold PR, Bellack AS: Diagnostic and demographic correlates of substance abuse: Implications for treatment. J Consult Clin Psychol 1992b;60:845-856.

51 Negus SS, Gatch MB, Mello NK: Discriminative stimulus effects of a cocaine/heroin 'speedball' combination in rhesus monkeys. J Pharmacol Exp Ther 1998;285:1123-1136.

52 Negus SS, Mello NK, Lamas X, Mendelson JH: Acute and chronic effects of flupenthixol on the discriminative stimulus and reinforcing effects of cocaine in rhesus monkeys. J Pharmacol Exp Ther 1996;278:879-889.

53 Nespor K, Prokes B, Brozek P, Bartáková O, Pekárková M: Flupentixol in the treatment of dependence (preliminary communication). Ceska Slovenska Psychiatrie 1999;6:387-390 (in Polish).

54 Preuss UW, Schütz CG, Koch J, Soyka M: Psychometrische Erfassung von subjektivem Craving mit der Obsessive Compulsive Drinking Scale (OCDS) und Einflüsse von Befindlichkeit und Persönlichkeit. Suchtmed 1999;1:33-38.

55 Pristach CA, Smith CM: Self-reported effects of alcohol use on symptoms of schizophrenia. Psychiatry Serv 1996;47:421-423.

56 Regier DA, Farmer ME, Rae DS, et al: Comorbidity of mental disorders with alcohol and other drug abuse: Results from the epidemiologica catchment area (ECA) study. JAMA 1990;264: 2511-2518.

57 Salyers MP, Mueser KT: Social functioning, psychopathology, and medication side effects in relation to substance use and abuse in schizophrenia. Schizophrenia Res 48;109123.

58 Schilkrut R, Cabrera J, Morales E, Herrera L: Neuroleptics in the treatment of drug dependence in schizophrenics: A study with flupenthixol decanoate. Psychopharmacology (Berl) 1988;96:342 (abstract)

59 Siris SG, Bermanzohn PC, Mason SE, Shuwall MA: Antidepressant for substance-abusing patients: A minireview. Prog Neuropsychopharmacol Biol Psychiatry 1991;15:1-13.

60 Siris SG, Mason SE, Bermanzohn PC, Shuwall MA, Aseniero A: Dual diagnosis/psychiatric comorbidity of drug dependence: Epidemiology and treatment. Psychopharmacol Bull 1993; 29:127-133.

61 Siris SG: Pharmacological treatment of substance abusing schizophrenic patients. Schizophrenia Bull 1990;16:111-122.

62 Smith J, Hucker S: Schizophrenia and Substance Abuse. Br J Psychiatry 1994;165:1321.

63 Sobell LC, Sobell MB: Timeline follow-back: A technique for assessing self-reported alcohol consumption; in Litten RZ, Allen JP (eds): Measuring Alcohol Consumption: Psychosocial and Biochemical Methods. Towota, $\mathrm{Hu}-$ mana Press, 1992 pp 41-72.
64 Soni SD, Brownlee M: Alcohol abuse in chronic schizophrenics: Implications for management in the community. Acta Psychiatr Scand 1991;84:272-276.

65 Soyka, M, Alcoholism and Schizophrenia. Addiction 2000;95:1613-1618.

66 Soyka M: Dual diagnosis in patients with schizophrenia. Issues in pharmacological treatment. CNS Drugs 1996;6:414-425.

67 Soyka M: Relapse prevention in patients with alcoholism: Recent advantages and future possibilities. CNS Drugs 1997;7:313-327.

68 Soyka M: Substance abuse, psychiatric disorder and disturbed behavior. Br J Psychiatry 2000;176:345-350.

69 Soyka M, Albus M, Finelli A, et al: Prevalence of alcohol and drug abuse in schizophrenic inpatients. Eur Arch Psychiatry Clin Neurosci 1993;242:362-372.

70 Soyka M, de Vry J: Flupenthixol as a potential pharmacotreatment of alcohol and cocaine abuse/dependence. Eur Neuropsychopharmacol, 2000;10:325-332.

71 Soyka M, Sand P: Successful treatment with flupenthixol decanoate of a patient with both schizophrenia and alcoholism. Pharmacopsychiatry $1995 ; 28: 64-65$.

72 Soyka M, Albus M, Immler B, Kathmann N, Hippius H: Psychopatholgy in dual diagnosis and non-addicted schizophrenics - Are there differences? Eur Arch Psychiatry Clin Neurosci 2001;251:232-238.

73 Stauning JA, Kirk L, Jørgensen A: Comparison of serum levels after intramuscular injections of 2 and $10 \%$ cis(Z)-Flupentixol decanoate in viscoleo to schizophrenic patients. Psychopharmacology (Berl) 1979;65:69-72.

74 Spealman RD, Bergman J, Madras BK, Meila KF: Discriminative stimulus of cocaine in squirrel monkeys: Involvement of dopamine receptor subtypes. J Pharmacol Exp Ther 1991; 258:945-953.

75 Tyrer P: Measurement of social functioning; in Tyrer P, Casey P (eds): Social Function in Psychiatry. The Hidden Axis of Classification Exposed. Petersfield, Wrightson Biomedical Publishing, 1993:21-52.

76 Vorungati LN, Heslegrave RJ, Awad AG: Neuroleptic dysphoria may be the missing link between schizophrenia and substance abuse. J Nerv Ment Dis 1997;185:463-465.

77 Wiesbeck GA, Weijers HG, Lesch OM, Glaser $\mathrm{T}$, Toennes PJ, Boening J: Flupenthixol decanoate and relapse prevention in alcoholics: Results from a placebo-controlled study. Alcohol Alcohol 2001;329-334.

78 Wilkins JN: Pharmacotherapy of schizophrenia patients with comorbid substance abuse. Schizophrenia Bull 1997;23:215-228.

79 Zimmet SV, Strous Rd, Burgess ES, Kohnstamm S, Green AI: Effects of clozapine on substance use in patients with schizophrenia and schizoaffective disorder: A retrospective survey. J Clin Psychopharmacol 2000;20:9498. 